\title{
MATRIX PRODUCTION AND COLLAGEN STRUCTURE ARE ENHANCED IN TWO TYPES OF OSTEOGENIC PROGENITOR CELLS BY A SIMPLE FLUID SHEAR STRESS STIMULUS
}

\author{
R. M. Delaine-Smith ${ }^{1}$, S. MacNeil ${ }^{1}$ and G. C. Reilly ${ }^{1 *}$
}

${ }^{1}$ Kroto Research Institute, Department of Materials Science and Engineering, University of Sheffield, Sheffield, UK.

\begin{abstract}
Mesenchymal progenitor cells play a vital role in bone regenerative medicine and tissue engineering strategies. To be clinically useful osteoprogenitors should be readily available with the potential to form bone matrix. While mesenchymal stromal cells from bone marrow have shown promise for tissue engineering, they are obtained in small numbers and there is risk of donor site morbidity. Osteogenic progenitor cells derived from dermal tissue may provide a more abundant and easily expandable source of cells. Bone turnover in vivo is regulated by mechanical forces, particularly oscillatory fluid shear stresses (FSS), and in vitro osteogenic progenitors have been shown to be regulated by mechanical stimuli. The aim of this study was to assess what effect osteogenic media and FSS, generated by a simple rocking platform, had on cell behaviour and matrix production in human progenitor dermal fibroblasts (HDFs) and the embryonic stem cell-derived mesenchymal progenitor cell line (hES-MP).

Osteogenic media stimulated alkaline phosphatase activity (ALP) and calcium deposition in HDFs. The addition of FSS further enhanced ALP activity and mineralised matrix deposition in both progenitor cells cultured in osteogenic media. Both types of progenitor cell subjected to FSS showed increases in collagen secretion and apparent collagen organisation as imaged by second harmonic generation.
\end{abstract}

Keywords: Mesenchymal stem cells; dermal fibroblasts; fluid shear stress; second harmonic generation; osteogenesis; matrix production; collagen.

*Address for correspondence:

Gwendolen Reilly

Department Materials Science and Engineering

Kroto Research Institute

University of Sheffield

Broad Lane

Sheffield, S3 7HQ, UK.

Telephone Number: +44 (0)114 2225986

FAX Number: +44 (0) 1142225945

E-mail: g.reilly@shef.ac.uk

\section{Introduction}

Mesenchymal progenitor cells play a vital role in bone regenerative medicine and tissue engineering strategies, and to be clinically useful they should be readily available with the potential to undergo osteogenesis. Mesenchymal stem or stromal cells (MSCs) harvested from bone marrow have shown great potential as an autologous bone cell source with self-renewing and multipotent properties capable of in vitro differentiation along the osteogenic lineage (Jaiswal et al., 1997; Mauney et al., 2004; Pittenger et al., 1999). However, bone marrow extraction carries the risk of donor site morbidity and only a small number of MSCs are obtained from bone marrow, which are difficult to expand to sufficient numbers in vitro. This has led researchers to search for alternative multipotent cell reservoirs. Progenitor cells with similar phenotypic characteristics and differentiation capabilities have been obtained from a variety of other adult tissues including adipose (De Ugarte et al., 2003; Zuk et al., 2001), tendon (Rui et al., 2011), and skeletal muscle (Asakura et al., 2001; Bosch et al., 2000), as well as foetal tissues such as umbilical cord blood (Erices et al., 2000; Goodwin et al., 2001) and amniotic fluid (Soncini et al., 2007). Another recently identified tissue that might harbour a suitable cell source for bone repair is the dermis of skin. Dermal fibroblasts were initially thought to be terminally differentiated, but it has been reported that dermal fibroblasts may be more plastic than first thought and are able to switch their lineage preference (Rutherford et al., 2002; Sommar et al., 2009) while numerous studies report that multipotent progenitor cells reside in the dermal tissue of rodents and humans (Bartsch et al., 2005; Chen et al., 2007; Toma et al., 2001; Xue and Li, 2011; Young et al., 2001). Chen et al. (2007) established single cell clones from dermal foreskin fibroblasts and found that around $30 \%$ upregulated alkaline phosphatase (ALP) and osteocalcin $(\mathrm{OCN})$ mRNA along with strong staining of deposited calcium when cultured in osteogenic media. Others have observed osteogenic differentiation from a population of skin cells (Buranasinsup et al., 2006; Lorenz et al., 2008). Lorenz et al. (2008) observed an upregulation in OCN and osteonectin (ON) mRNA in cells derived from human juvenile foreskin when cultured in osteogenic media, while Buranasinsup et al. (2006) observed positive ALP and mineral staining in cells derived from middleage human skin biopsies. This suggests that dermal tissue has the potential to be an easily accessible source of cells suitable for use in bone tissue engineering.

MSC behaviour and function can be controlled by biochemical stimuli such as growth factors, cytokines and signalling events (Augello and De Bari, 2010) as well as 
physical and environmental cues (e.g. surface chemistry and topography) (Dalby et al., 2007; Reilly and Engler, 2010). More recently, researchers have become aware that mechanical forces can also have an influence on MSC behaviour and may be important in directing their differentiation and maturation to obtain a fully-developed tissue engineered construct. It has been shown in vivo that mechanical forces regulate bone mass and strength (Bassey and Ramsdale, 1994; Janmey and McCulloch, 2007). Some of the major forces that contribute to the mechanical environment of bone cells are oscillatory fluid shear stresses (FSS) caused by fluid movement through interstitial bone space as a result of repetitive loading and unloading of the bone. It is also thought that oscillatory FSS would be experienced by cells in the bone marrow cavity. The magnitude of FSS in mature bone have been predicted to be in the range of 0.8-3 $\mathrm{Pa}$ (Weinbaum et al., 1994) and although the magnitude of the FSS in bone marrow are not known, they are predicted to be much less due to the higher porosity and lower stiffness of the marrow (Gurkan and Akkus, 2008). Recent in vitro stimulation of osteoprogenitors using FSS have shown that osteogenic differentiation can be induced or enhanced on $2 \mathrm{D}$ substrates as well as $3 \mathrm{D}$ scaffolds, see recent reviews Delaine-Smith and Reilly (2011) and McCoy and O'Brien (2010). At present there are no studies that we know of that have looked at what effect the combination of osteogenic supplements and oscillatory FSS have on dermal fibroblasts.

While it is has been established that mechanical forces can influence MSC differentiation, it is still not clear what the best conditions are to achieve this. This is mainly due to the number of parameters that are relevant - the magnitude of the force, the number of cycles, the length of stimulation and the number of rest periods. Therefore, a simple system that is capable of mechanically stimulating large numbers of samples and testing a wide variety of parameters, which also allows for easy monitoring of cell differentiation and matrix production, would be ideal. It has been suggested that a rocking 'see-saw' system holding culture wells containing media is able to create FSS suitable for stimulating cells (Zhou et al., 2010; Tucker et al., 2011 ). This simple system is an easily accessible device that has many advantages over other more commonly used apparatus including smaller amounts of medium per sample, cheap and easy operation, no special chambers required and high throughput. Therefore, this system seems ideal for testing a wide range of fluid flow regimes and how they influence the osteogenic differentiation of progenitor cells in a rapid and straightforward manner. The simplicity of the apparatus also allows for fast and easy monitoring of the production of the major bone matrix protein, collagen, by conventional methodologies and, as we assess in this study, by non-invasive monitoring using second harmonic generation (SHG). SHG is a multiphoton-based technique, which allows the imaging of non-centrosymmetric molecules such as collagen (Bayan et al., 2009). The collagen molecule is excited by two near-infrared incident photons, which come together to produce a visible photon with exactly half the wavelength and twice the energy. This photon can be detected at half the wavelength of that used to excite the sample and the intensity of the resulting SHG image is influenced by the quantity of collagen present as well as the fibril organisation (Bayan et al., 2009; Matcher, 2009).

In summary, this study had three objectives. The first was to use a simple platform rocking model to mechanically stimulate a mature osteoblastic cell line (MLO-A5) and osteogenic progenitor cells to see if the FSS created could influence their differentiation and matrix production. The second was to examine if osteogenic media and FSS were able to induce dermal fibroblasts to an osteogenic lineage. The third objective was to monitor the effect FSS had on the production and organisation of cell secreted tissue engineered collagen using SHG.

\section{Methods}

\section{Cell culture}

Three cell types were used in this study: primary human dermal fibroblasts (HDFs) isolated from dermal tissue taken from one consenting patient undergoing surgery (procedures were approved by the National Health Service Research ethics committee); the human embryonic cellderived mesenchymal progenitor cell line hES-MP 002.5 (hES-MP) (Cellartis, Gothenburg, Sweden); and the late stage osteoblast/early stage osteocyte mouse cell line MLO-A5 kindly donated by Professor Lynda Bonewald (University of Missouri, Kansas City, MO, USA) under a Material Transfer Agreement with the University of Texas. HDFs were expanded in basal media, which consisted of Dulbecco's modified Eagle's medium (DMEM) (Biosera, Ringmer, UK) supplemented with $10 \%$ foetal calf serum (FCS), $2 \mathrm{mM}$ L-glutamine and $100 \mathrm{mg} / \mathrm{mL}$ penicillin and streptomycin $(\mathrm{P} / \mathrm{S})$. MLO-A5 and hES-MP cells were cultured in basal $\alpha$-media, which consisted of Minimum Essential Alpha Medium ( $\alpha$-MEM) (Lonza, Verviers, Belgium) containing $10 \%$ FCS, 2 mM L-glutamine and $100 \mathrm{mg} / \mathrm{mL} \mathrm{P} / \mathrm{S}$ and seeded onto gelatine coated T-75 flasks. All cells were incubated at $37{ }^{\circ} \mathrm{C}$ in the presence of $5 \% \mathrm{CO}_{2}$ and fresh media changes were made every 2-3 d. For each experiment, hES-MPs were used between passages 3-7 and cultured in either basal $\alpha$-media with $50 \mathrm{mg} / \mathrm{mL}$ ascorbic acid-2-phosphate (AA) and $5 \mathrm{mM}$ $\beta$-glycerophosphate ( $\beta \mathrm{GP}$ ) (non-Dex containing media (NM)), or basal $\alpha$-media with $50 \mathrm{mg} / \mathrm{mL} \mathrm{AA,} 5 \mathrm{mM} \beta \mathrm{GP}$ and $100 \mathrm{nM}$ dexamethasome (Dex) (osteogenic media $(\mathrm{OM})$ ). HDFs were used between passages 2-3 and were cultured either in the presence of fibroblastic media (FM) containing basal media with $50 \mu \mathrm{g} / \mathrm{mL}$ AA, or in OM. MLO-A5 cells were cultured in NM and used between passages 25-30. All reagents were obtained from SigmaAldrich (Gillingham, UK) unless otherwise stated.

\section{Application of fluid shear stress}

For experiments, all cells were seeded onto gelatine-coated standard 6-well plates at a density of 10,000 cells per well in their respective basal media. Media with supplements were added $24 \mathrm{~h}$ after attachment. Cells of each media type were either cultured under static conditions (no forces) or subjected to fluid shear stresses (FSS) (also referred to as 'rocked' group) starting from day 4 of culture at 45 cycles/ 
min for $1 \mathrm{~h}$ per day, for 5 days per week. The rocking platform had a maximum tilt angle of 6 degrees and each well contained $2 \mathrm{~mL}$ of media. Bouts of rocking were performed outside of an incubator and static controls were also placed outside of the incubator for the same period of time. Media was changed every 2-3 days. The FSS generated were calculated for three separate points in space along the well bottom using a lubrication-based model previously described by Zhou et al. (2010) for a circular well. Values of FSS were obtained using the equation for calculating the characteristic shear stress (Eq. 1), where $\mu$ is the fluid viscosity $\left(10^{-3} \mathrm{~Pa} \mathrm{~s}\right), \theta_{\max }$ is the maximal flip angle, $\delta$ is the ratio of the fluid depth to the well length, and $T$ is the time for one cycle. Briefly, the model assumes that fluid movement is mainly driven by gravity, and that the fluid free surface remains horizontal. Secondly, the centrifugal forces acting on the fluid are neglected due to the low angular acceleration and velocity.

$$
\left|\tilde{\tau}_{w}\right|=\frac{\pi \mu \theta_{\max }}{2 \delta^{2} T}
$$

\section{Cellular morphology}

Cellular morphology was visualised at day 7 using fluorescence microscopy. DAPI (4',6-diamidino-2phenylindole dihydrochloride) $(1 \mu \mathrm{g} / \mathrm{mL})$ and phalloidin TRITC (phalloidin-tetramethylrhodamine B isothiocyanate) $(1 \mu \mathrm{g} / \mathrm{mL})$ (Sigma) staining were used for the cell nucleus and the cell actin-cytoskeleton, respectively, and images were captured using an Image Express ${ }^{\mathrm{TM}}$ fluorescent microscope (Axon Instruments, Wokingham, UK) using the built-in $\mathrm{x} 20$ objective and preset DAPI and Rhodamine filters. Images from DAPI and phalloidin TRITC channels were combined using ImageJ software.

\section{Alkaline phosphatase activity and total DNA measurement}

Total DNA was measured using a fluorescent QuantiT ${ }^{\mathrm{TM}}$ PicoGreen ${ }^{\circledR}$ dsDNA reagent assay kit (Invitrogen, Paisley, UK) per the manufacturer's instructions. Briefly, cells were lysed in a carbonate buffer solution and freezethawed three times before a known volume of cell lysate was added to the provided Tris-buffered EDTA solution. The Quant-iT ${ }^{\mathrm{TM}}$ PicoGreen ${ }^{\circledR}$ reagent was then added, which binds to double-stranded DNA in solution, and fluorescence intensity was recorded using a FLx800 microplate fluorescence reader (BioTek, Potten, UK) using $485 \mathrm{~nm}$ excitation and $520 \mathrm{~nm}$ emission. Total DNA was converted to ng DNA/sample from a standard curve. ALP activity in the cells was assessed using a colorimetric assay; a known quantity of cell lysate was added to a p-nitrophenol phosphate substrate (Sigma) and the subsequent conversion to p-nitrophenyl was measured by recording the rate of colour change from colourless to yellow at $405 \mathrm{~nm}$. ALP activity was calculated as nmol of substrate converted per minute using a standard curve and then normalised to total DNA.

\section{Collagen and calcium staining}

Total cellular collagen production was quantified at days 7, 14 and 21 by staining the deposited collagen using a $0.1 \%$ Picrosirius red solution (Sigma) for $1 \mathrm{~h}$ on a platform shaker. The unbound Picrosirius red solution was washed away by three washes with deionised water and the resulting stain was removed with methanol:0.2 $\mathrm{M} \mathrm{NaOH}$ (1:1) for $10 \mathrm{~min}$ on a platform shaker. The absorbance of the resulting solution was then measured at $490 \mathrm{~nm}$ on a 96-well plate reader. Calcium deposition by the cells was visualised at day 21 by staining with a $1 \%$ Alizarin red solution for $15 \mathrm{~min}$ (Sigma). Excess Alizarin solution was removed by washing with deionised water five times and then deposited calcium was quantified by removing the Alizarin stain with $5 \% \mathrm{v} / \mathrm{v}$ perchloric acid for $10 \mathrm{~min}$ and reading the absorbance of the resulting solution at $405 \mathrm{~nm}$.

\section{Second harmonic generation (SHG)}

Deposited collagen fibres were visualised from SHG images obtained using a Zeiss Axioskop 2 FS MOT (Carl Zeiss MiroImaging, Jena, Germany) laser-scanning confocal microscope equipped with a tuneable Chameleon Ti:sapphire multiphoton laser (Coherent, Santa Clara, CA, USA). Excitation of the samples was performed at $940 \mathrm{~nm}$ and SHG emission was collected in the backwards scattering direction and filtered through a primary dichroic (HFT KP650) before entering a descanned LSM 510 Meta detector (Carl Zeiss MicroImaging) set with a narrow $10 \mathrm{~nm}$ bandpass filter centred around $469 \mathrm{~nm}$ with the pinhole set to maximum. Samples of all conditions were imaged at days 7, 14 and 21 of culture using a 40x NA 1.3 Plan Neofluar oil immersion objective (Carl Zeiss MicroImaging) focused on the central region of each sample with a power of $20 \mathrm{~mW}$.

\section{Statistics}

All rocker experiments were performed two or three times with triplicate samples for each condition $(n=6$ or 9). For collagen visualisation using SHG, one sample of each condition was imaged at each time point $(n=2-3)$, with images being obtained from the centre region approximately $10 \mu \mathrm{m}$ into the sample. Cells of the same type and cultured using the same media conditions were compared for significant differences between statically cultured and rocked groups using an unpaired Student's $t$-test. All graphs are mean $\pm \mathrm{SD}$ and significant differences are marked for $p<0.05$ and $p<0.01$.

\section{Results}

\section{Fluid shear stress profiles}

The FSS at the base of the culture wells were calculated at 3 separate points in space $(\mathrm{x} / \mathrm{L}=0.25,0.5,0.75$, where $\mathrm{x}$ is the distance from the edge of the well and $\mathrm{L}$ is the diameter of the well) along the middle of the well parallel to the fluid movement during one rocking cycle. The FSS varied in a spatiotemporal fashion and were oscillatory in nature (Fig. 1a-b). Under the conditions used, the shear stress at the centre of the well $(\mathrm{x} / \mathrm{L}=0.5)$ was found to vary in a sinusoidal manner peaking at $0.041 \mathrm{~Pa}$, while at the other two locations $(\mathrm{x} / \mathrm{L}=0.25$ or 0.75$)$ the stress peaked at $0.051 \mathrm{~Pa}$ and deviated from a typical sinusoidal wave. The stress profiles at locations $\mathrm{x} / \mathrm{L}=0.25$ and 0.75 were identical except for a phase difference of 180 degrees. 
(a)

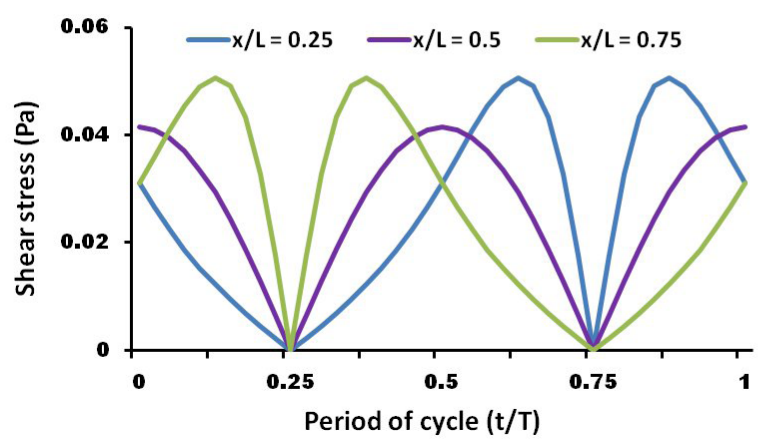

(b)

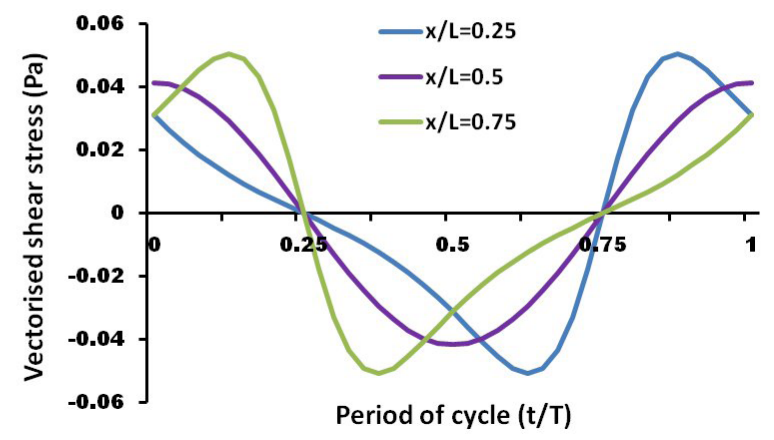

Fig. 1. (a) Calculated shear stress profiles for one cycle experienced at the base of a 6-well plate for three different locations, $\mathrm{x} / \mathrm{L}=0.25,0.5$, or 0.75 , where $\mathrm{x}$ is the distance from the edge of the well and $\mathrm{L}$ is the diameter of the well. (b) The oscillatory nature of the fluid flow-induced shear stresses indicated by positive and negative stress.

(a)

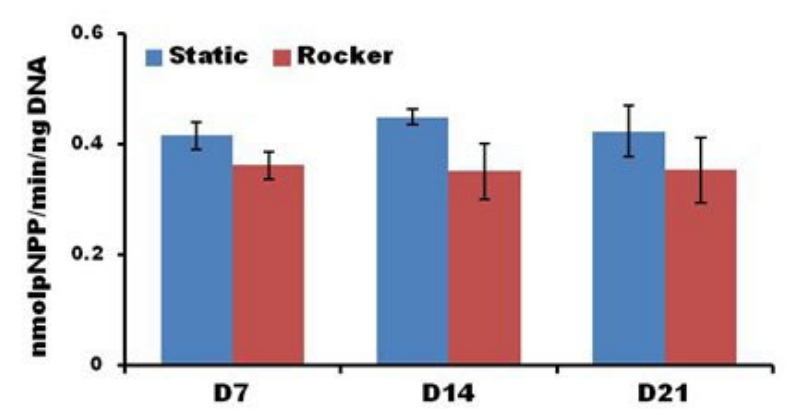

(c)

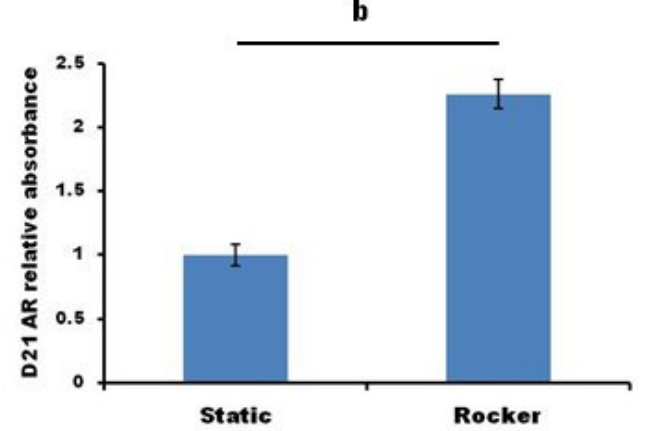

(b)

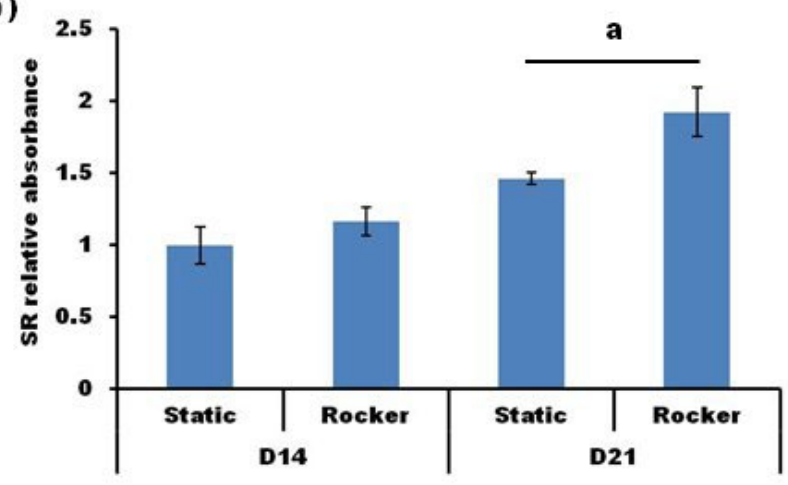

(d)

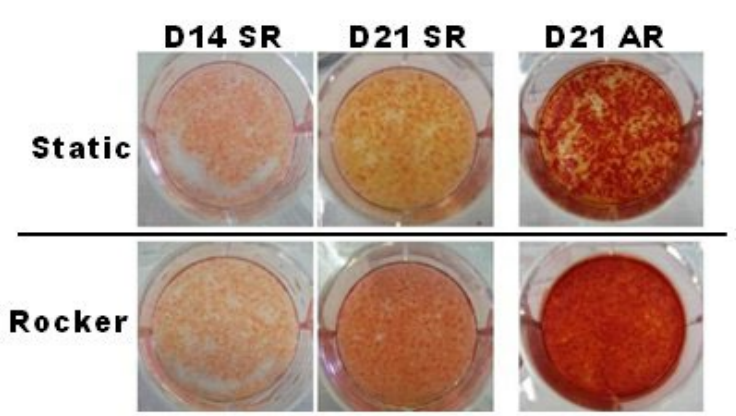

Fig. 2. The affect of FSS on MLO-A5s. (a) ALP activity normalised to total DNA; (b) total collagen production assayed by Picrosirius red staining; (c) calcium deposition assessed by Alizarin red; (d) Picrosirius red and Alizarin red staining of MLO-A5 cells at day 14 and 21 under static or rocked conditions (individual wells of a 6-well plate are shown). All bar graphs are mean $\pm \mathrm{SD}(n=9)$. Significant differences between static and rocked cells are a $=$ $p<0.05$ and $\mathrm{b}=p<0.01$.

\section{The effect of FSS on matrix formation by MLO-A5} cells

The ALP activity of MLO-A5 cells peaked in both static and rocked groups at day 7 and remained constant up to days 14 and 21 (Fig. 2a). Cells exposed to rocking appeared to have $15 \%$ lower ALP activity across all three time points but this was not statistically significant. Collagen production measured at day 14 was not affected by rocking, but by day 21 samples exposed to rocking had $25 \%$ more secreted collagen than static controls (Fig. 2b). Calcium deposition assayed at day 21 was 2-fold higher when cells were subjected to rocking (Fig. 2c). At day 21 collagen and calcium staining in the rocked groups appeared more uniform across the culture dish, whereas statically cultured groups showed patchy staining (Fig. 2d).

\section{The effect of FSS on the morphology of progenitor cells}

hES-MP cells cultured under static conditions in non-Dex containing media (NM) had a fibroblastic, spindle-shaped morphology, whereas hES-MPs cultured in osteogenic media (OM) were larger and more cuboidal in shape, indicative of an osteoblastic cell (Fig. 3a). HDFs cultured in fibroblastic media (FM) showed a typical fibroblastic morphology, however when cultured in OM they showed a more cuboidal morphology (Fig. 3b) similar to the hES-MP 

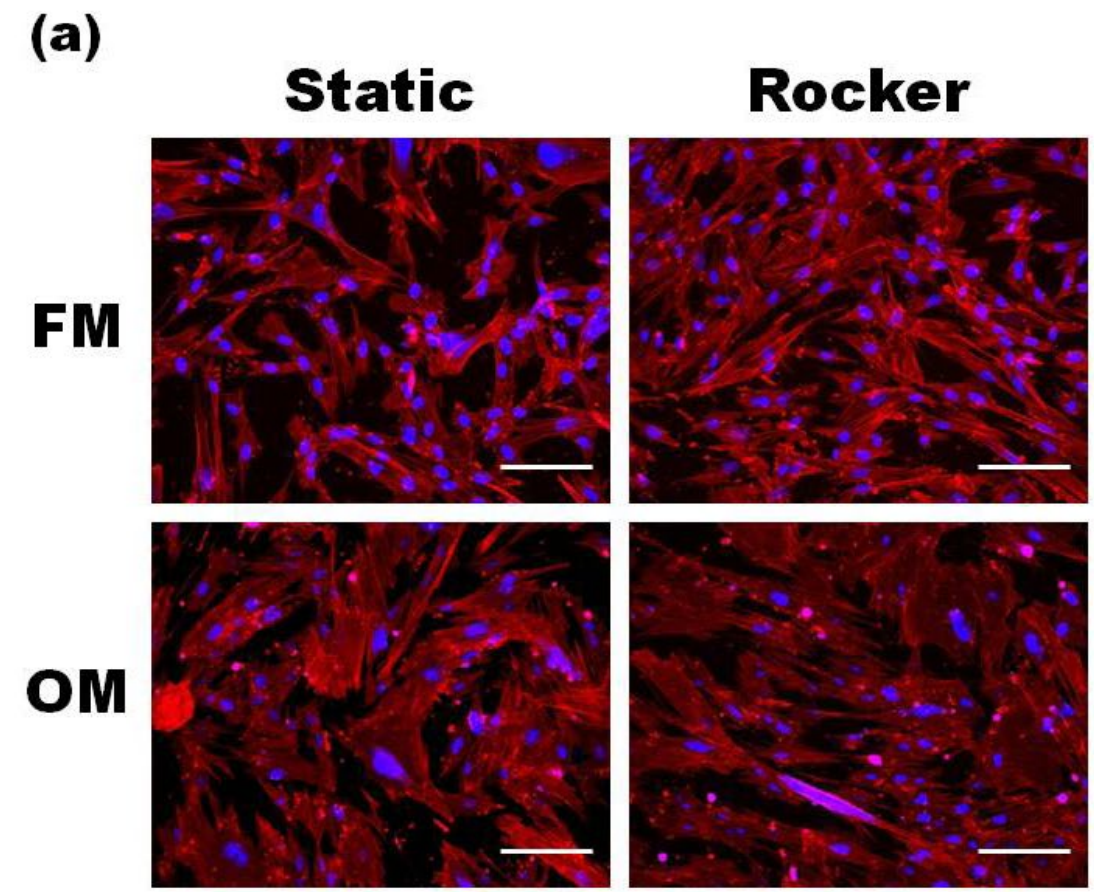

\section{hESMPS}

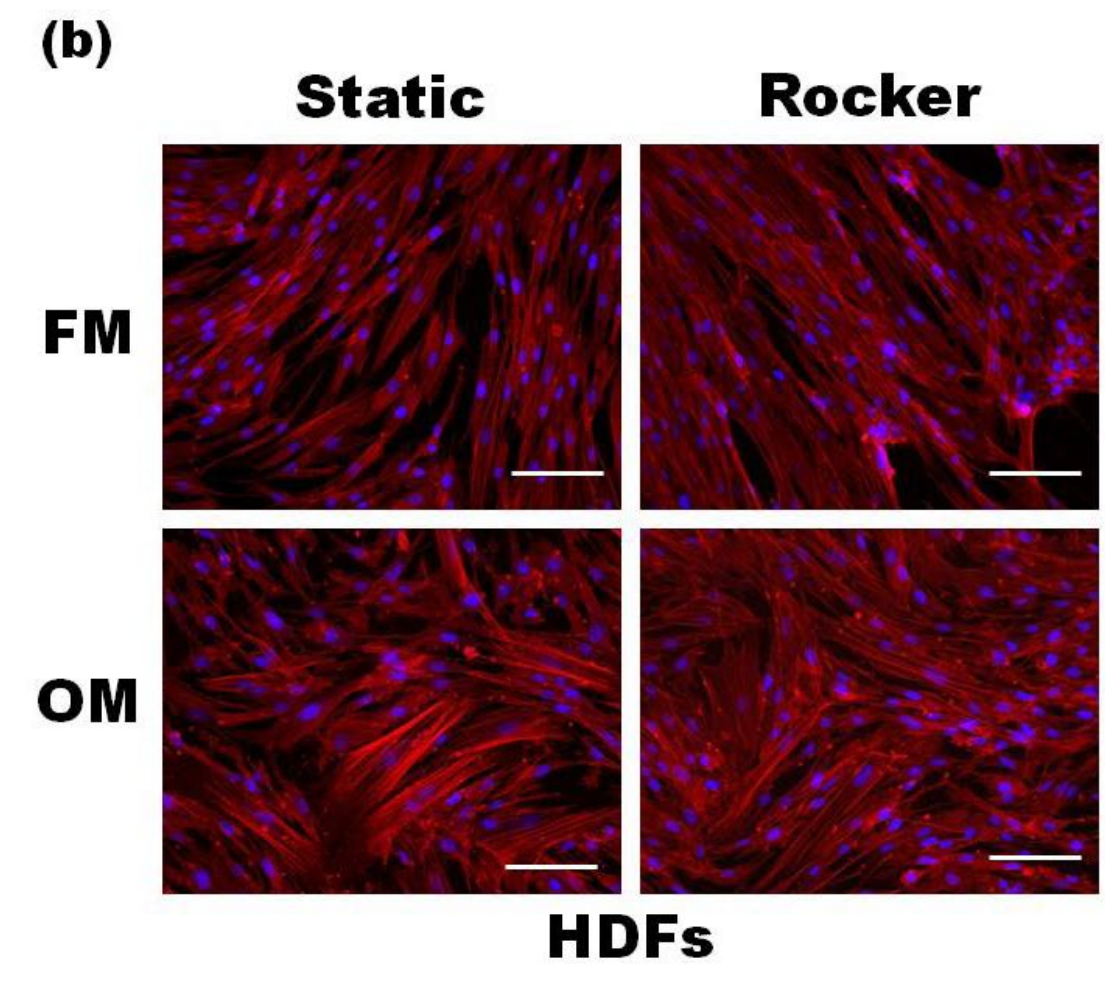

Fig. 3. Fluorescent DAPI staining of cell nucleus (blue) and phalloidin TRITC staining of cell actin cytoskeleton (red). (a) hES-MP cells cultured in either non-Dex containing media (NM) or osteogenic media (OM) under static or rocked conditions; or (b) HDFs cultured in either fibroblastic media (FM) or OM under static or rocked conditions. Cells cultured in FM or NM show a more fibroblastic morphology, whereas cells cultured in OM show a more osteoblastic morphology. (Scale bars are $100 \mu \mathrm{m}$ ).

cells and generally appeared larger than those cultured in FM. Cellular alignment did not appear to be influenced by fluid flow induced by rocking in any areas of the culture well for either cell type.

The effect of FSS on total DNA and ALP activity of progenitor cells

Total DNA content, an indicator of total cell number, increased for both cell types in all cell groups between days 7 and 14 and then remained constant up to day 21 (Fig. 4a-b). There were no statistically significant differences in total DNA between cells that were rocked or cultured under static conditions but it was noticed that hES-MP cells cultured in OM did have $20 \%$ less DNA at days 14 and 21 compared with cells cultured in NM. Normalised ALP activity increased in both cell types for all cell groups up to day 21 (Fig. 4c-d), however no ALP activity was detectable in any HDF culture group at day 7. ALP activity in hES-MPs was an order of magnitude higher in OM cultured cells compared to those cultured in NM. 
(a)

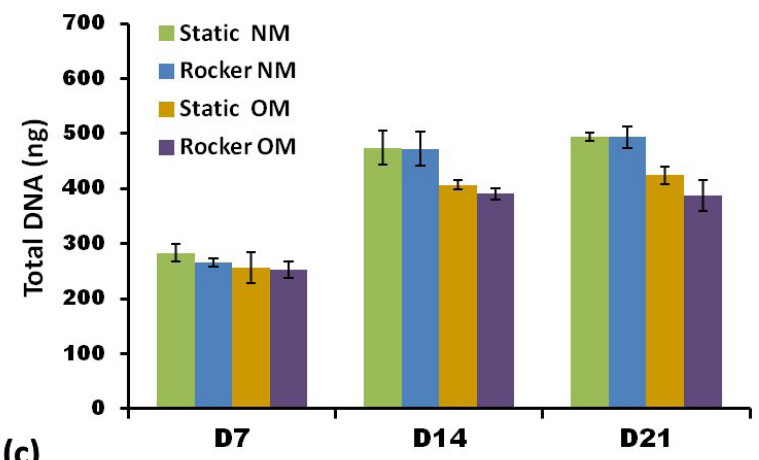

(c)

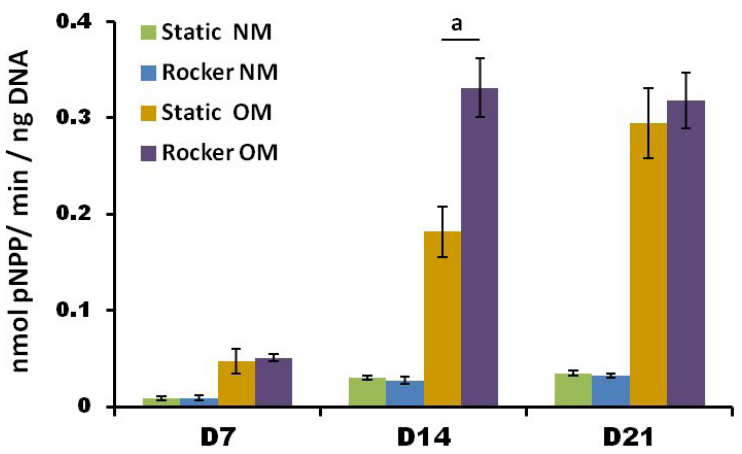

(b)
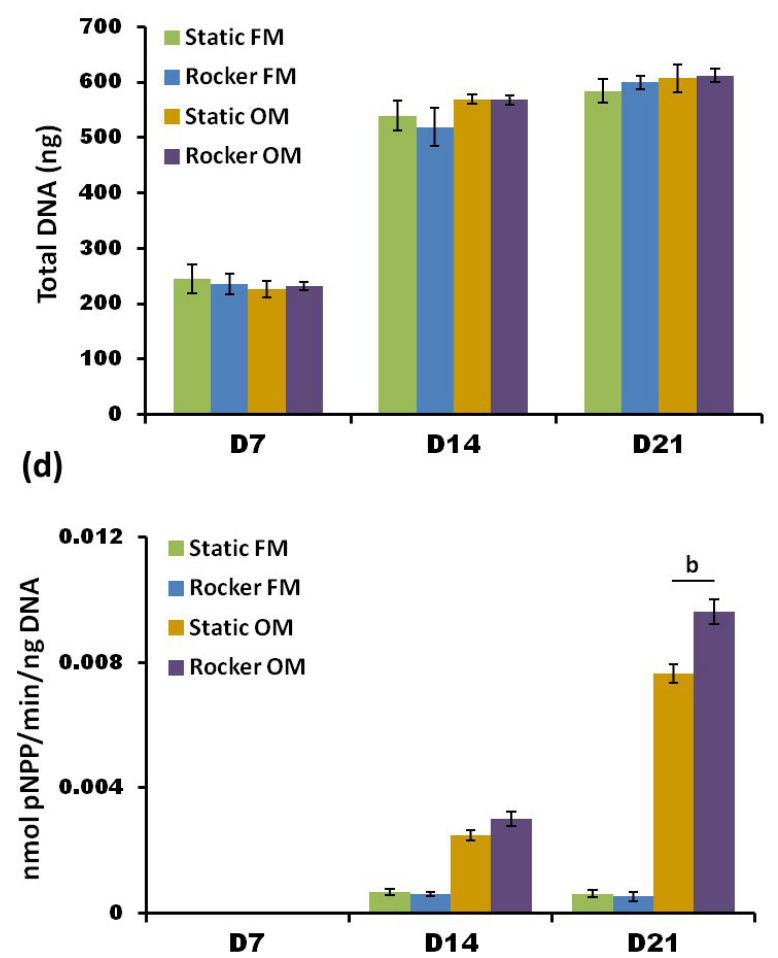

Fig. 4. The effect of FSS on total DNA content of hES-MPs (a) and HDFs (b) and ALP activity (plotted normalised to total DNA) for hES-MPs (c) and HDFs (d) measured at days 7, 14 and 21. FSS did not affect total DNA for any cell groups, but did cause statistically significant higher normalised ALP activity in Dex-treated cell groups. ALP activity in non-Dex-treated groups was minimal and FSS did not enhance this. Note the y axis range for HDFs is smaller than that for hES-MPs due to lower ALP activity. All bar graphs are mean $\pm \mathrm{SD}(n=9)$ and significant differences between static and rocked cells are $\mathrm{a}=p<0.01$ and $\mathrm{b}=p<0.05$.

When OM was combined with rocking, ALP activity in hES-MPs was 2-fold higher at day 14 compared with their static counterparts. It appears that the rocking accelerated the upregulation of ALP activity, as by day 21 the static controls were as high as the rocked samples. However, there was no effect seen when NM was combined with rocking. HDFs cultured in FM did not produce enough detectable ALP above baseline values at any time point; when cultured in OM they began producing detectable levels of ALP at day 14, and by 21 these levels had increased 4 times compared to day 14 . When OM cultured HDFs were subjected to FSS, ALP activity increased by $20 \%$ over static counterparts at day 21 , which was statistically significant.

\section{The effect of FSS on total collagen and calcium production by progenitor cells}

Total collagen production quantified by Picrosirius red staining showed that cells cultured with Dex had produced less collagen at all time points, compared to those cultured without Dex (Fig. 5a-b). For hES-MPs cultured in either media group, the application of rocking caused the total amount of collagen deposited by day 21 to be $20 \%$ higher $(p<0.05)$ (Fig. 5a). For HDFs subjected to rocking, significantly more total collagen $(p<0.01)$ was seen at days 14 and 21 for both media groups (Fig. 5b). Calcium deposition assayed at day 21 was 3 -fold higher in Dex treated hES-MPs subjected to rocking compared to static counterparts and this staining was more uniform across the culture dish while static cells showed patchy staining (Fig. 5c). In comparison, HDFs cultured in OM showed a relatively small amount of calcium staining at day 21 but rocking significantly increased the amount deposited by $50 \%$ (Fig. 5d). The Alizarin stain was seen to concentrate more around the centre of the wells and became fainter towards the outside of the well. Both hES-MP cells and HDFs cultured without Dex did not produce any calcium as visualised by the absence of Alizarin red stain.

\section{Assessment of collagen production by second harmonic generation}

The effect of FSS on collagen deposition and maturation was monitored in both HDFs and hESMP cells using SHG at days 7, 14 and 21 (Fig. 6a-b). Signal intensity increased for all samples from day 7 to 21 , indicating an accumulation of collagen over the culture period. When both cell types were cultured in the presence of Dex, the signal intensity was lower at all time points compared to those cultured without Dex. When both cell types were cultured without Dex and subjected to rocking, an increase in SHG signal was seen at all time points compared with static counterparts. It was not until day 21 that a noticeable difference in SHG intensity was seen for both cell types when cultured in OM, with those subjected to rocking giving a stronger signal compared with statically cultured counterparts. Rocking appeared to have a smaller effect on 
(a)

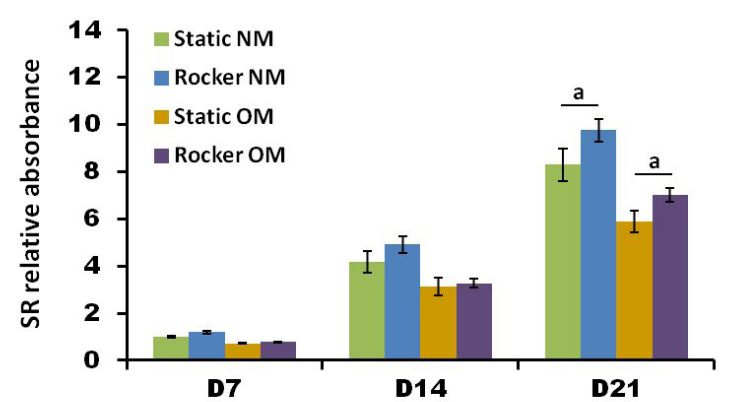

(c)
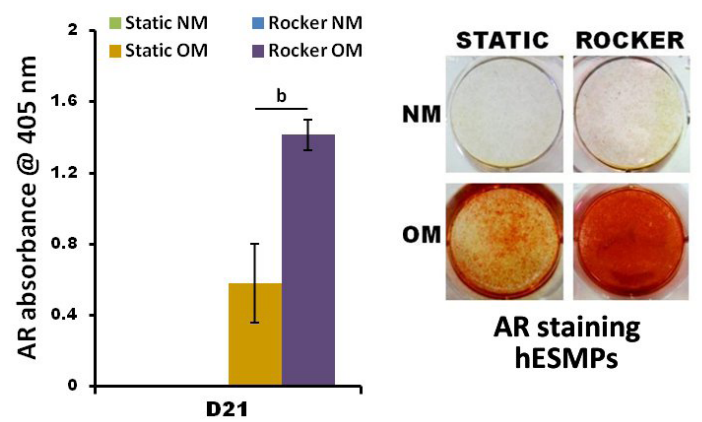

(b)

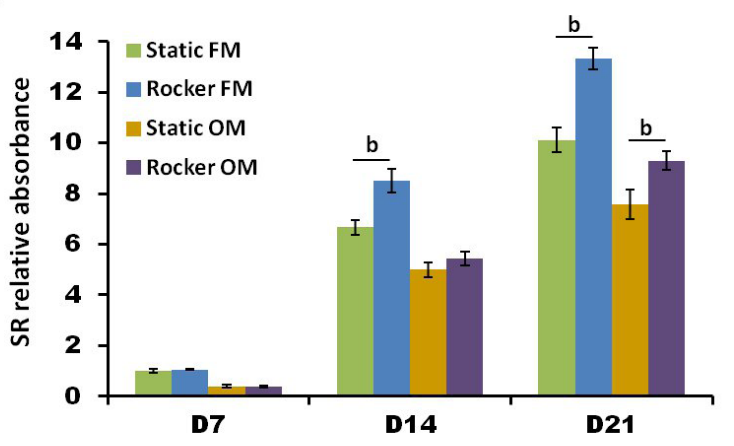

(d)

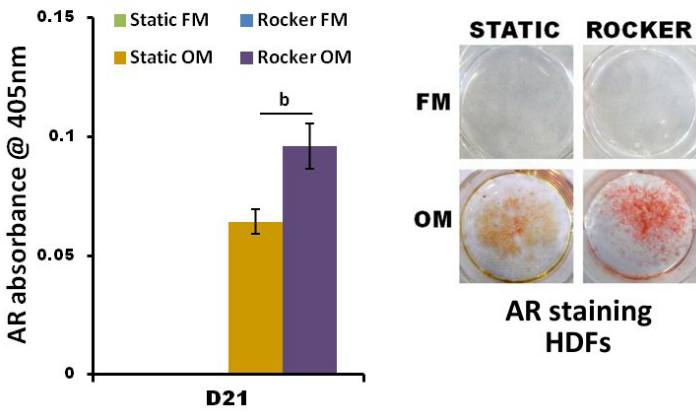

Fig. 5. Total collagen production at days 7, 14 and 21 as quantified by Picrosirius red staining for hES-MPs (a) and HDFs (b). The application of FSS caused a statistically significant increase in collagen deposition for all cells at day 21, and cells treated with Dex produced less collagen than those without Dex. Calcium deposition was visualised at day 21 by Alizarin red staining for hES-MPs (c) and HDFs (d) and the application of FSS caused an increase in the amount of deposited calcium. Non-Dex-containing media (FM and NM) or FSS alone did not induce calcium deposition. Calcium was quantified from the Alizarin red stain. All bar graphs are mean $\pm \operatorname{SD}(n=6$ for collagen; $n=9$ for calcium) and significant differences between static and rocked cells are $\mathrm{a}=p<0.05$ and $\mathrm{b}=p<0.01$.

SHG intensity in hES-MP cells (Fig. 6a) than in HDFs (Fig. 6b) when compared with static counterparts. While rocking did not appear to induce a preferred direction of collagen orientation with either cell type in any media groups, rocking did appear to improve collagen organisation at day 14 and even more clearly at day 21 . Statically cultured groups showed short and disorganised collagen fibres, whereas FSS groups had thicker and longer bundles of fibres and this effect was more evident in groups cultured without Dex.

\section{Discussion}

Our aims were to undertake research towards progressing tissue engineering of bone towards the clinic - examining a convenient possible source of osteogenic progenitor cells, assessing a simple methodology to apply mechanical stimulation to these cells, and monitoring collagen production and orientation using the minimally invasive technique of SHG.

This study was the first, to our knowledge, to use a simple platform rocking method to directly stimulate progenitor cells using oscillatory FSS for enhancing osteogenic differentiation. This is also the first study we know of to subject dermal fibroblasts and the hES-MP cell line to oscillatory FSS for the purpose of stimulating the production of a mineralised collagenous matrix. Although it has been demonstrated that osteoprogenitor MSCs respond to a variety of mechanical stimuli in a range of 2D and 3D bioreactor conditions (Delaine-Smith and Reilly, 2011), here we present the interesting result that dermal fibroblasts cultured in osteogenic media produce a mineralised collagenous matrix that is further enhanced by oscillatory FSS. The reasons for selecting HDFs for use in this study is that isolating progenitor cells from the dermis would have many advantages over other osteoprogenitor sources in that any donor will have large quantities of easily accessible skin and operations to remove it are simple and less painful than procedures to remove bone marrow. HDFs also have a high proliferative potential and can be expanded into large numbers in vitro.

The FSS calculated in this study were much lower than those estimated to occur within mature bone (0.8-3 Pa (Weinbaum et al., 1994)), peaking at $0.041 \mathrm{~Pa}$ in the well centre, and are also much lower than the FSS generally used by others for mechanically stimulating osteoblastic cells, particularly in 2D (McCoy and O'Brien, 2010). However, the mature osteoblast MLO-A5 cell line responded to the shear forces with a noticeable increase in collagen and calcium production at day 21 . Collagen production and organisation was improved in both the hES-MP cells and the HDFs when subjected to these FSS. When cultured in combination with osteogenic media, both cell types upregulated ALP activity and calcium production. Previous studies have also shown that hMSCs cultured in osteogenic supplements are mechanosensitive to relatively small shear 
(a)

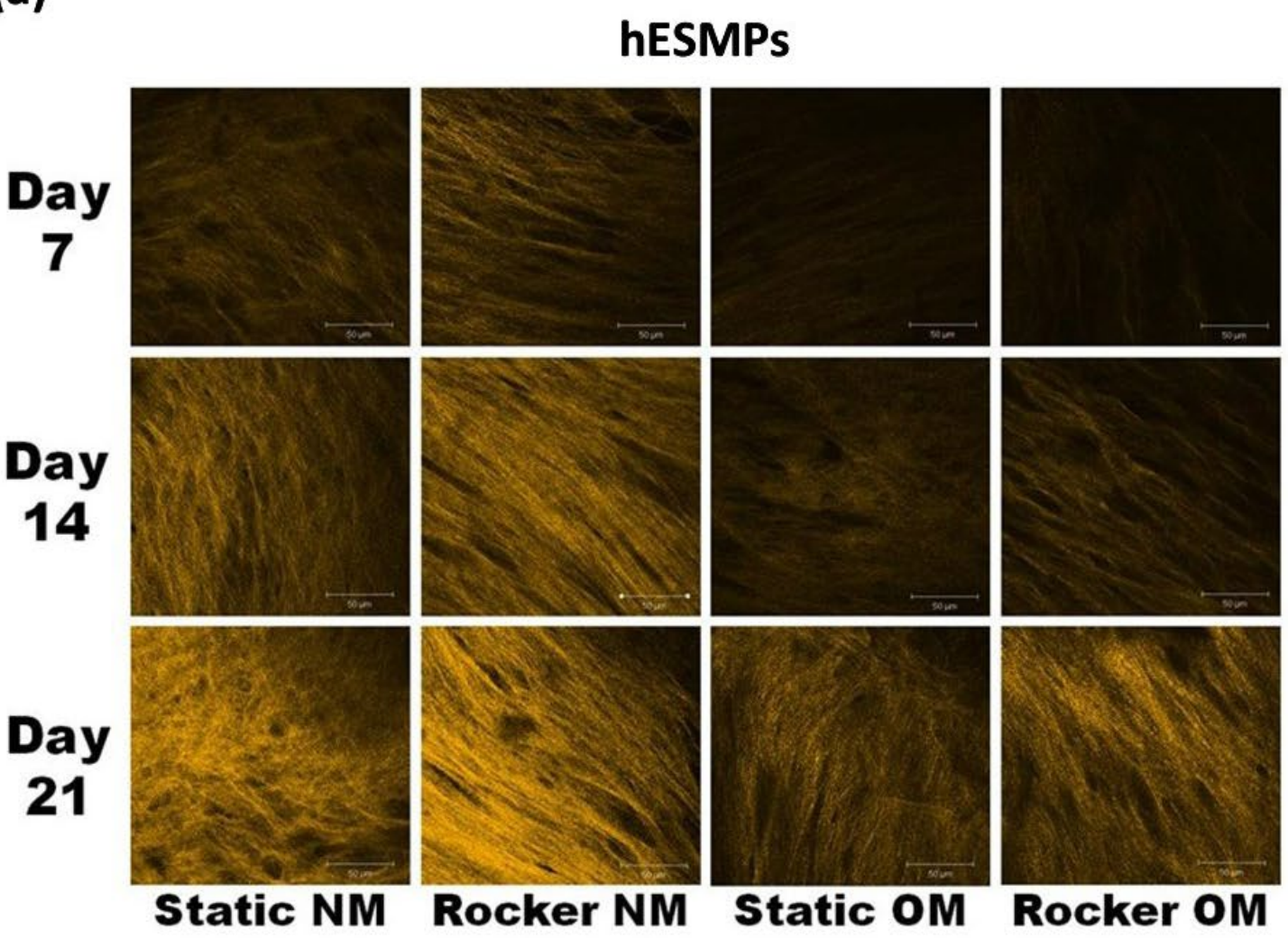

(b)
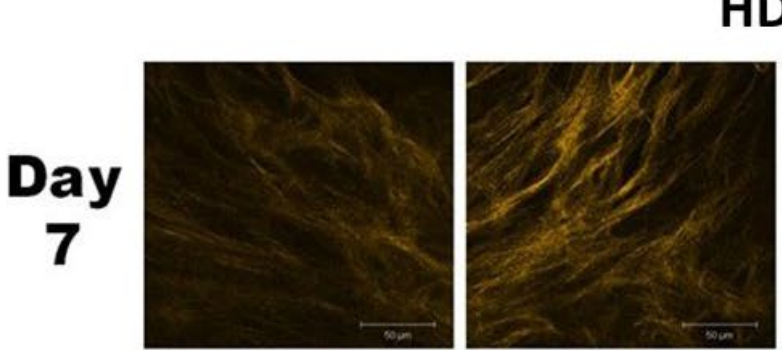

HDFs

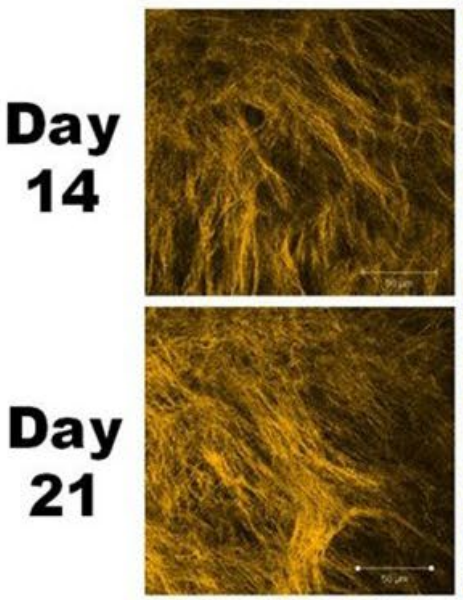

Static FM
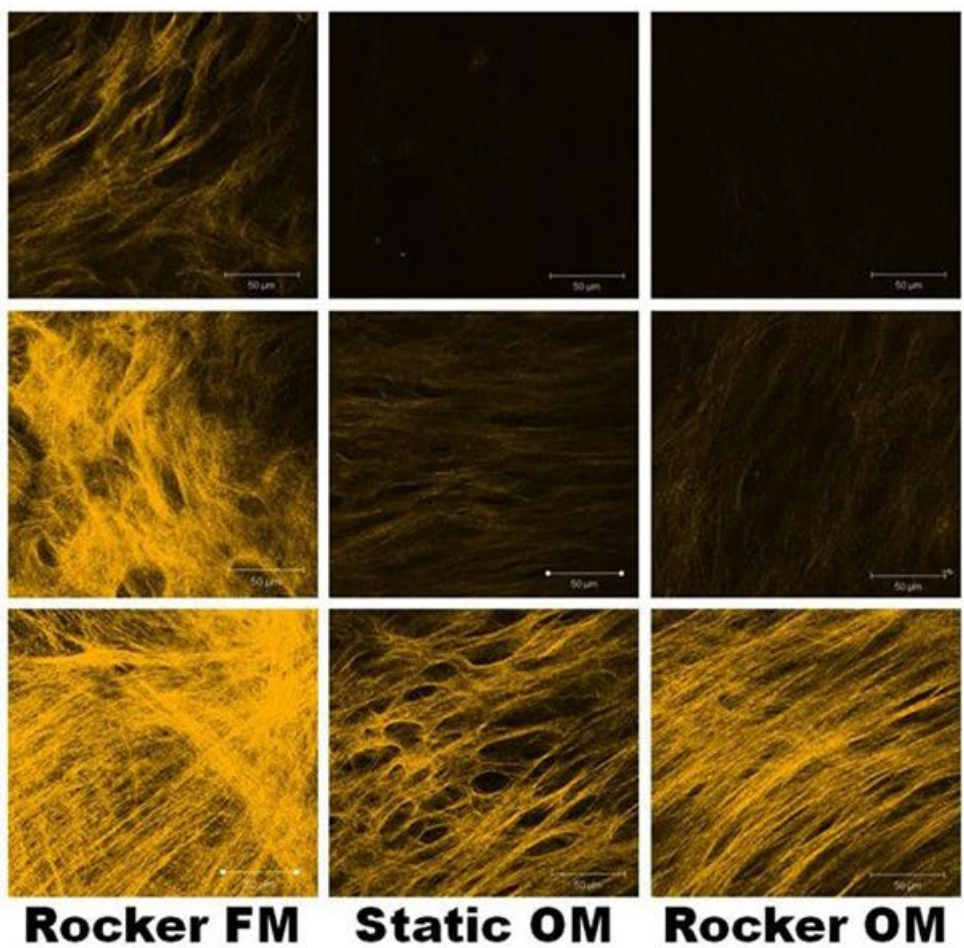

Static OM

Rocker OM

Fig. 6. Second harmonic generation (SHG) images of deposited collagen produced by hES-MPs (a) and HDFs (b) at days 7, 14 and 21. Increases in collagen deposition and organisation are indicated by an increase in SHG intensity and area coverage. A more organised collagen matrix can be observed in cells subjected to FSS, indicated by the appearance of thicker collagen bundles and more defined fibres. Images with a dark appearance did not produce enough detectable SHG signal (Scale bars are $50 \mu \mathrm{m}$ ). 
forces $(0.036 \mathrm{~Pa})$ applied for only short periods of time (Kreke et al., 2005). In a recent study, a T-75 flask rocking system was used to stimulate osteoblasts and osteocytes to condition media for MSCs (Hoey et al., 2011), and although they did not calculate the FSSs present, it is likely they would have also been relatively low. It is unclear whether tissue engineers should be attempting to replicate the mature bone environment or rather a developmental or fracture-healing environment where bone cells differentiate in vivo. Immature, developing bone tissue resembles a healing wound and not a mature tissue and so the forces experienced are likely to be different from those of a fully developed tissue, although little is known about what these forces are (Willie et al., 2010).

The shear stress profiles and the peak shear force varied for different locations within the well plate, but the resulting calcium staining for MLO-A5 cells and hESMPs showed a rather uniform pattern across the well. This indicates that either the range of forces being experienced by the cells have a similar effect on their differentiation or that the cells are communicating with each other, such as via gap junctions (Donahue, 2000; Taylor et al., 2007). Another contributing factor could be that the fluid flow is inducing chemotransport (Donahue et al., 2003) and so biochemical factors regulating bone cell metabolism, such as prostaglandin $\mathrm{E}_{2}$ (Genetos et al., 2005), are released into the media by the cells and moved around due to mass transport. While we did not test the mechanisms by which fluid flow enhances osteogenic differentiation, the data presented combined with other studies suggests that osteoblastic differentiation may be guided by soluble factors that accumulate in the media from a combination of externally applied chemical stimulants and direct mechanical stress on the cells (Hoey et al., 2011).

MLO-A5s are a late stage osteoblast/early stage osteocyte murine cell line that mineralise rapidly (8$10 \mathrm{~d}$ ) even in the absence of $\beta$ GP (Kato et al., 2001) and they have been shown to respond to bouts of mechanical conditioning with enhanced matrix production (Morris et al., 2010; Sittichokechaiwut et al., 2010). MLO-A5s express high levels of ALP activity due to their advanced stage of maturity and FSS were not seen to have a significant effect on these levels at the selected time points, but calcium production was increased 2 -fold. ALP activity is present in the early stages of osteogenesis and also plays a part in the initial stages of mineralisation via its enzymatic hydrolysis activity (Yadav et al., 2011).

This study showed that hES-MPs and HDFs cultured in osteogenic media had significantly higher ALP activity than those cultured in non-Dex containing media and this level continued to rise up to day 21. Some authors report ALP activity as a biphasic process, rising to a peak level before gradually decreasing again (Bancroft et al., 2002; Datta et al., 2006), but this was not seen here. FSS increased ALP activity in both sets of progenitor cells when cultured in osteogenic media and both cells subsequently increased their calcium deposition. ALP activity in the hES-MPs was at least ten-fold higher than that in HDFs. The hES-MPs are a relatively homogeneous population of cells derived from a single source of embryonic stem cells already characterised as mesenchymal lineage specific and able to undergo osteogenesis in induction media (Karlsson et al., 2009). However, HDFs are a much more variable cell population from a mature adult donor and it is likely that only a sub-population of the cells can undergo osteogenic differentiation, or that the cells have varying levels of differentiation potential (Chen et al., 2007).

Cells derived from dermal tissue have previously been reported to show osteogenic differentiation potential (Bartsch et al., 2005; Chen et al., 2007) and this study showed that HDFs produced ALP and deposited calcium when cultured in osteogenic supplements. Previous studies have tended to culture HDFs under static conditions but this study showed that the application of oscillatory FSS could further enhance this osteogenic differentiation. In a previous study by Sommar et al. (2009), HDFs were cultured in a macroporous gelatine construct in the presence of osteogenic media and subjected to FSS in a rotating spinner flask. They noticed the formation of bonelike tissue, with further enhancements in the amount of deposited mineral in constructs cultured in spinner flasks. This observation, along with the present study, suggests that FSS can enhance mineralised matrix in HDFs cultured in osteogenic media. This revelation that HDFs can be induced towards an osteogenic phenotype using osteogenic supplements and FSS highlights their potential use in the repair of bone. A limitation of our study was that only HDFs from one patient were used and as with other progenitor populations, there will be cell variability resulting from variations in the source of tissue, such as tissue type and location within the body, donor characteristics, or in vitro passaging conditions.

Fibroblasts were only used to passage 3 because after this they did not consistently make calcium at day 21 , although they did continue to up-regulate ALP activity to similar levels (data not shown). The majority of studies have used dermal fibroblast populations taken from foetal or juvenile skin (Lavoie et al., 2009; Xue and Li, 2011), with the authors reporting loss of osteogenic potential or decreased potential at higher passage numbers. Some have reported that dermal progenitor populations display a delayed differentiation potential, often taking longer to mineralise than other MSC populations, anywhere between 4-8 weeks (Buranasinsup et al., 2006; Jaager and Neuman, 2011; Lorenz et al., 2008). However, there are a number of studies that have shown osteogenic differentiation to occur in cells from mature and aged dermis (Xue and Li, 2011; Young et al., 2001). This loss of differentiation potential and donor variation could be a potential limitation with the future use of these cells for autologous bone repair, and so it is clear that more studies from a larger number of donors are required to assess their bone forming potential.

Monitoring matrix development by progenitor cells is very important for a successful tissue construct to be developed. Collagen type 1 fibres are the primary component of the organic portion of bone ECM and are well organised into orientated concentric layers in Haversian systems. This also provides the foundation for mineral deposition, and so it has a crucial role in bone formation. The amount of collagen present and how it is 
organised plays a major role in determining the mechanical properties of the tissue. While some studies have shown that mechanical forces alone can induce osteogenic differentiation in MSCs (Chen et al., 2008; Sumanasinghe et al., 2006; Yourek et al., 2010), in this study FSS alone did not enhance calcium deposition. However, FSS did increase collagen production in all cells under all conditions and this has been seen in other studies using fluid flow as a stimulatory source (Augst et al., 2008; Morris et al., 2010; Sharp et al., 2009). When hES-MP cells and HDFs were treated with Dex, they produced less collagen at all time points, compared with those cultured without Dex. This is visualised very clearly from the SHG images (Fig. 6) and this is the first study that we know of to show the true extent of this effect of Dex on collagen production using SHG. It has been reported that MSCs treated with Dex in vitro show a reduction in collagen production (Leboy et al., 1991; Ogston et al., 2002) and large concentrations of Dex used to treat patients for various conditions can cause bone loss or impairment of bone formation leading to osteoporosis (Scutt et al., 1996). Cells subjected to FSS also appeared to be more organised into thicker and longer bundles of fibres when imaged using SHG; information that could not be obtained from Picrosirius red staining. This enhanced collagen organisation suggests that cells subjected to these FSS would produce tissues with stronger tensile properties.

The process of converting mechanical stimulation into a biochemical response, mechanotransduction, is thought to occur through a number of mechanically-sensitive mechanisms including the cytoskeleton and integrins, ion channels, the glycocalyx and the primary cilia (Jacobs et al., 2010; Morris et al., 2010; Reilly et al., 2003; Weinbaum et al., 2007). Through these mechanisms, the application of FSS initiates a number of signalling events, including the synthesis and release of nitric oxide and prostaglandins (Klein-Nulend et al., 2005), a calcium signalling response and phosphorylation of the mitogenactivated protein (MAP) kinase ERK (You et al., 2001). During osteogenic differentiation, the actin cytoskeleton in hMSCs remodels resulting in a morphological switch from a fibroblastic fusiform shape to a square shape which is more osteoblast-like. This was observed to happen with the hES-MP cells cultured in osteogenic media and a very similar morphological switch was observed when HDFs were cultured in osteogenic media. When subjected to flow, both cells appeared to be more elongated in either media condition. This is thought to be due to a stiffening of the cell cytoskeleton, and it has been seen that stiffer cells tend to become more mechano-responsive perhaps due to the forces being transmitted more efficiently (Yourek et al., 2010). Previous studies have shown that actin cytoskeletal tension is required for the activation of mechanosensors or signalling mechanisms involved in the regulation of intracellular processes and protein expression resulting from FSS (Arnsdorf et al., 2009). Also a number of studies have shown that remodelling of the cell cytoskeleton can induce changes in the organisation and distribution of deposited collagen (Brammer et al., 2009; Koepsell et al., 2011).

\section{Conclusions}

Isolating progenitor cells from the dermis for use as an autologous source of bone cells would have many advantages in that any donor will have large quantities of easily accessible skin and biopsies undertaken under local anaesthetic to remove it are straightforward. However, more work is needed to fully characterise this apparently diverse pool of multipotent cells in order to realise their full capabilities, including determining the effect that patient age and in vitro passaging conditions may have on their bone forming potential. The effect that mechanical forces have on progenitor cells is now a major research focus for musculoskeletal tissue engineers and their potential to aid healing and direct differentiation are being realised. The simple system employed here created FSS that enhanced osteogenic differentiation in mature bone cells and bone progenitor cells in the presence of osteogenic supplements. Using SHG, we saw an enhanced production and organisation of the major bone matrix protein collagen caused by FSS. This system has many advantages in that it is simple to use, can be used with many experimental samples, and could be easily scaled up for large defects. This system could be used for a number of tissue engineering strategies, such as pre-treating cells before injection into a scaffold or directly into a tissue defect or for stimulating cells cultured on thin scaffold sheets to be layered to form a 3D implantable tissue.

\section{Acknowledgments}

We gratefully acknowledge funding from the Engineering and Physical Sciences Research Council. Dr Steven Matcher, University of Sheffield kindly provided advice on the SHG technique. Imaging work was performed at the Kroto Research Institute Confocal Imaging Facility, using the LSM510 Meta confocal microscope, thanks to Nicola Green for facility maintenance and technical assistance. We wish to confirm that there are no known conflicts of interest associated with this publication and there has been no significant financial support for this work that could have influenced its outcome.

\section{References}

Arnsdorf EJ, Tummala P, Kwon RY, Jacobs CR (2009) Mechanically induced osteogenic differentiation - the role of RhoA, ROCKII and cytoskeletal dynamics. J Cell Sci 122: 546-553.

Asakura A, Komaki M, Rudnicki MA (2001) Muscle satellite cells are multipotential stem cells that exhibit myogenic, osteogenic, and adipogenic differentiation. Differentiation 68: 245-253.

Augello A, De Bari C (2010) The regulation of differentiation in mesenchymal stem cells. Hum Gene Ther 21: 1226-1238.

Augst A, Marolt D, Freed LE, Vepari C, Meinel L, Farley M, Fajardo R, Patel N, Gray M, Kaplan DL, Vunjak-Novakovic G (2008) Effects of chondrogenic and osteogenic regulatory factors on composite constructs 
grown using human mesenchymal stem cells, silk scaffolds and bioreactors. J R Soc Interface 5: 929-939.

Bancroft GN, Sikavitsas VI, van den Dolder J, Sheffield TL, Ambrose CG, Jansen JA, Mikos AG (2002) Fluid flow increases mineralized matrix deposition in $3 \mathrm{D}$ perfusion culture of marrow stromal osteoblasts in a dose-dependent manner. Proc Natl Acad Sci USA 99: 12600-12605.

Bartsch G, Yoo JJ, De Coppi P, Siddiqui MM, Schuch G, Pohl HG, Fuhr J, Perin L, Soker S, Atala A (2005) Propagation, expansion, and multilineage differentiation of human somatic stem cells from dermal progenitors. Stem Cell Dev 14: 337-348.

Bassey EJ, Ramsdale SJ (1994) Increase in femoral bone-density in young-women following high-impact excercise. Osteoporosis Int 4: 72-75.

Bayan C, Jonathan ML, Miller E, Kaplan D, Georgakoudi I (2009) Fully automated, quantitative, noninvasive assessment of collagen fiber content and organiaztion in thick collagen gels. J Appl Phys 105: 102042

Bosch P, Musgrave DS, Lee JY, Cummins J, Shuler F, Ghivizzani SC, Evans C, Robbins PD, Huard J (2000) Osteoprogenitor cells within skeletal muscle. J Orthop Res 18: $933-944$.

Brammer KS, Oh S, Cobb CJ, Bjursten LM, van der Heyde H, Jin S (2009) Improved bone-forming functionality on diameter-controlled $\mathrm{TiO}(2)$ nanotube surface. Acta Biomater 8: 3215-3223.

Buranasinsup S, Sila-asna M, Bunyaratvej N, Bunyaratvej A (2006) In vitro osteogenesis from human skin-derived precursor cells. Dev Growth Differ 48: 263269.

Chen FG, Zhang WJ, Bi D, Liu W, Wei X, Chen FF, Zhu L, Cui L, Cao Y (2007) Clonal analysis of nestin(-) vimentin $(+)$ multipotent fibroblasts isolated from human dermis. J Cell Sci 120: 2875-2883.

Chen YJ, Huang CH, Lee IC, Lee YT, Chen MH, Young TH (2008) Effects of cyclic mechanical stretching on the mRNA expression of tendon/ligament-related and osteoblast-specific genes in human mesenchymal stem cells. Connect Tissue Res 49: 7-14.

Dalby MJ, Gadegaard N, Tare R, Andar A, Riehle MO, Herzyk P, Wilkinson CDW, Oreffo ROC (2007) The control of human mesenchymal cell differentiation using nanoscale symmetry and disorder. Nat Mater 6: 997-1003.

Datta N, Pham QP, Sharma U, Sikavitsas VI, Jansen JA, Mikos AG (2006) In vitro generated extracellular matrix and fluid shear stress synergistically enhance 3D osteoblastic differentiation. Proc Natl Acad Sci USA 103: 2388-2493.

De Ugarte DA, Morizono K, Elbarbary A, Alfonso Z, Zuk PA, Zhu M, Dragoo JL, Ashjian P, Thomas B, Benhaim P, Chen I, Fraser J, Hedrick MH (2003) Comparison of multi-lineage cells from human adipose tissue and bone marrow. Cells Tissues Organs 174: 101-109.

Delaine-Smith RM, Reilly GC (2011) The effects of mechanical loading on mesenchymal stem cell differentiation and matrix production. Vitam Horm 87: 417-480.

Donahue HJ (2000) Gap junctions and biophysical regulation of bone cell differentiation. Bone 26: 417-422.
Donahue TLH, Haut TR, Yellowley CE, Donahue HJ, Jacobs CR (2003) Mechanosensitivity of bone cells to oscillating fluid flow induced shear stress may be modulated by chemotransport. J Biomech 36: 1363-1371.

Erices A, Conget P, Minguell JJ (2000) Mesenchymal progenitor cells in human umbilical cord blood. Brit $\mathrm{J}$ Haematol 109: 235-242.

Genetos DC, Geist DJ, Liu DW, Donahue HJ, Duncan RL (2005) Fluid shear-induced ATP secretion mediates prostaglandin release in MC3T3-E1 osteoblasts. J Bone Miner Res 20: 41-49.

Goodwin HS, Bicknese AR, Chien SN, Bogucki BD, Oliver DA, Quinn CO, Wall DA (2001) Multilineage differentiation activity by cells isolated from umbilical cord blood: Expression of bone, fat, and neural markers. Biol Blood Marrow Transplant 7: 581-588.

Gurkan UA, Akkus O (2008) The mechanical environment of bone marrow: a review. Ann Biomed Eng 36: 1978-1991.

Hoey DA, Kelly DJ, Jacobs CR (2011) A role for the primary cilium in paracrine signaling between mechanically stimulated osteocytes and mesenchymal stem cells. Biochem Biophys Res Commun 412: 182-187.

Jaager K, Neuman T (2011) Human dermal fibroblasts exhibit delayed adipogenic differentiation compared with mesenchymal stem cells. Stem Cell Dev, 20: 1327-1336.

Jacobs CR, Temiyasathit S, Castillo AB (2010) Osteocyte mechanobiology and pericellular mechanics. Ann Rev Biomed Eng 12: 369-400.

Jaiswal N, Haynesworth SE, Caplan AL, Bruder SP (1997) Osteogenic differentiation of purified, cultureexpanded human mesenchymal stem cells in vitro. J Cell Biochem 64: 295-312.

Janmey PA, McCulloch CA (2007) Cell mechanics: Integrating cell responses to mechanical stimuli. Ann Rev Biomed Eng 9: 1-34.

Karlsson C, Emanuelsson K, Wessberg F, Kajic K, Axell MZ, Eriksson PS, Lindahl A, Hyllner J, Strehl R (2009) Human embryonic stem cell-derived mesenchymal progenitors. Potential in regenerative medicine. Stem Cell Res 3: 39-50.

Kato Y, Boskey K, Spevak L, Dallas M, Hori M, Bonewald LF (2001) Establishment of an osteoid preosteocyte-like cell MLO-A5 that spontaneously mineralizes in culture. J Bone Miner Res 16: 1622-1633.

Klein-Nulend J, Bacabac RG, Mullender MG (2005) Mechanobiology of bone tissue. Pathol Biol 53: 576-580.

Koepsell L, Remund T, Bao J, Neufield D, Fong H, Deng Y (2011) Tissue engineering of annulus fibrosus using electrospun fibrous scaffolds with aligned polycaprolactone fibers. J Biomed Mater Res Part A 4: 564-575.

Kreke MR, Huckle WR, Goldstein AS (2005) Fluid flow stimulates expression of osteopontin and bone sialoprotein by bone marrow stromal cells in a temporally dependent manner. Bone 36: 1047-1055.

Lavoie JF, Biernaskie JA, Chen Y, Bagli D, Alman B, Kaplan DR, Miller FD (2009) Skin-derived precursors differentiate into skeletogenic cell types and contribute to bone repair. Stem Cell Dev 18: 893-905.

Leboy PS, Beresford JN, Devlin C, Owen ME (1991) Dexamethasone induction of osteoblast messenger-RNAs 
in rat marrow stromal cell-cultures. J Cell Physiol 146: 370-378.

Lorenz K, Sicker M, Schmelzer E, Rupf T, Salvetter J, Schulz-Siegmund M, Bader A (2008) Multilineage differentiation potential of human dermal skin-derived fibroblasts. Exp Dermatol 17: 925-932.

Matcher S (2009) A review of some recent developments in polarization-sensitive optical imaging techniques for the study of articular cartilage. J Appl Phys 105: 102041.

Mauney JR, Blumberg J, Pirun M, Volloch V, Vunjak-Novakovic G, Kaplan DL (2004) Osteogenic differentiation of human bone marrow stromal cells on partially demineralized bone scaffolds in vitro. Tissue Eng 10: 81-92.

McCoy RJ, O’Brien FJ (2010) Influence of shear stress in perfusion bioreactor cultures for the development of three-dimensional bone tissue constructs: A review. Tissue Eng Part B Rev 16: 587-601.

Morris HL, Reed CI, Haycock JW, Reilly GC (2010) Mechanisms of fluid-flow-induced matrix production in bone tissue engineering. Proc Inst Mech Eng H, 224: 1509-1521.

Ogston N, Harrison AJ, Cheung HFJ, Ashton BA, Hampson G (2002) Dexamethasone and retinoic acid differentially regulate growth and differentiation in an immortalised human clonal bone marrow stromal cell line with osteoblastic characteristics. Steroids 67: 895-906.

Pittenger MF, Mackay AM, Beck SC, Jaiswal RK, Douglas R, Mosca JD, Moorman MA, Simonetti DW, Craig S, Marshak DR (1999) Multilineage potential of adult human mesenchymal stem cells. Science 284: 143-147.

Reilly GC, Engler AJ (2010) Intrinsic extracellular matrix properties regulate stem cell differentiation. J Biomech 43: 55-62.

Reilly GC, Haut TR, Yellowley CE, Donahue HJ, Jacobs CR (2003) Fluid flow induced PGE(2) release by bone cells is reduced by glycocalyx degradation whereas calcium signals are not. Biorheology 40: 591-603.

Rui YF, Lui PPY, Ni M, Chan LS, Lee YW, Chan KM (2011) Mechanical loading increased BMP-2 expression which promoted osteogenic differentiation of tendonderived stem cells. J Orthop Res 29: 390-396.

Rutherford RB, Moalli M, Franceschi RT, Wang D, Gu K, Krebsbach PH (2002) Bone morphogenetic proteintransduced human fibroblasts convert to osteoblasts and form bone in vivo. Tissue Eng 8: 441-452.

Scutt A, Bertram P, Brautigam M (1996) The role of glucocorticoids and prostaglandin $\mathrm{E}(2)$ in the recruitment of bone marrow mesenchymal cells to the osteoblastic lineage: Positive and negative effects. Calcified Tissue Int 59: 154-162.

Sharp LA, Lee YW, Goldstein AS (2009) Effect of low-frequency pulsatile flow on expression of osteoblastic genes by bone marrow stromal cells. Ann Biomed Eng 37: 445-453.

Sittichokechaiwut A, Edwards JH, Scutt AM, Reilly GC (2010) Short bouts of mechanical loading are as effective as dexamethasone at inducing matrix production by human bone marrow mesenchymal stem cells. Eur Cells Mater 20: 45-57.
Sommar P, Pettersson S, Ness C, Johnson H, Kratz G, Junker JPE (2009) Engineering three-dimensional cartilage- and bone-like tissues using human dermal fibroblasts and macroporous gelatine microcarriers. J Plast Reconstr Aesthet Surg 63: 1036-1046.

Soncini M, Vertua E, Gibelli L, Zorzi F, Denegri M, Albertini A, Wengler GS, Parolini O (2007) Isolation and characterization of mesenchymal cells from human fetal membranes. J Tissue Eng Regen Med 1: 296-305.

Sumanasinghe RD, Bernacki SH, Loboa EG (2006) Osteogenic differentiation of human mesenchymal stem cells in collagen matrices: Effect of uniaxial cyclic tensile strain on bone morphogenetic protein (BMP-2) mRNA expression. Tissue Eng 12: 3459-3465.

Taylor AF, Saunders MM, Shingle DL, Cimbala JM, Zhou Z, Donahue HJ (2007) Mechanically stimulated osteocytes regulate osteoblastic activity via gap junctions. Am J PhysiolCell Physiol 292: C545-C552.

Toma JG, Akhavan M, Fernandes KJL, Barnabe-Heider F, Sadikot A, Kaplan DR, Miller FD (2001) Isolation of multipotent adult stem cells from the dermis of mammalian skin. Nat Cell Biol 3: 778-784.

Tucker RP, Franklin S, Okech W, Chen D, Ventikos Y, Thompson MS (2011) Validated in vitro cyclic shear stress alters human tenocyte ECM synthesis. Histol Histopathol 26 (suppl 1): 27.P6.

Weinbaum S, Cowin SC, Zeng Y (1994) A model for the excitation of osteocytes by mechanical loading-induced bone fluid shear stress. J Biomech 27: 339-360.

Weinbaum S, Tarbell JM, Damiano ER (2007) The structure and function of the endothelial glycocalyx layer. Ann Rev Biomed Eng 9: 121-167.

Willie BM, Petersen A, Schmidt-Bleek K, Cipitria A, Mehta M, Strube P, Lienau J, Wildemann B, Fratzl P, Duda G (2010) Designing biomimetic scaffolds for bone regeneration: why aim for a copy of mature tissue properties if nature uses a different approach? Soft Matter 6: 4976-4987.

Xue S, Li L (2011) Upregulation of collagen type 1 in aged murine dermis after transplantation of dermal multipotent cells. Clin Exp Dermatol 36: 775-781.

Yadav MC, Simao AMS, Narisawa S, Huesa C, McKee MD, Farquharson C, Millan JL (2011) Loss of skeletal mineralization by the simultaneous ablation of PHOSPHO1 and alkaline phosphatase function: A unified model of the mechanisms of initiation of skeletal calcification. J Bone Miner Res 26: 286-297.

You J, Reilly GC, Zhen XC, Yellowley CE, Chen Q, Donahue HJ, Jacobs CR (2001) Osteopontin gene regulation by oscillatory fluid flow via intracellular calcium mobilization and activation of mitogen-activated protein kinase in MC3T3-E1 osteoblasts. J Biol Chem 276: 13365 13371.

Young HE, Steele TA, Bray RA, Hudson J, Floyd JA, Hawkins K, Thomas K, Austin T, Edwards C, Cuzzourt J, Duenzl M, Lucas PA, Black AC (2001) Human reserve pluripotent mesenchymal stem cells are present in the connective tissues of skeletal muscle and dermis derived from fetal, adult, and geriatric donors. Anat Rec 264: 5162. 
Yourek G, McCormick SM, Mao JJ, Reilly GC (2010) Shear stress induces osteogenic differentiation of human mesenchymal stem cells. Regen Med, 5:713-724.

Zhou XZ, Liu DW, You LD, Wang LY (2010) Quantifying fluid shear stress in a rocking culture dish. J Biomech 43: 1598-1602.

Zuk PA, Zhu M, Mizuno H, Huang J, Futrell JW, Katz AJ, Benhaim P, Lorenz HP, Hedrick MH (2001) Multilineage cells from human adipose tissue: Implications for cell-based therapies. Tissue Eng 7: 211-228.

\section{Discussion with Reviewers}

Reviewer I: Why use ESC derived MSC and not bone marrow/adipose derived? Are the authors satisfied that these are a good representation and what surface markers are they positive for?

Authors: The human embryonic stem cell-derived mesenchymal progenitor (hES-MP) cell line are free of undifferentiated hESC markers (Oct-4, TRA 1-60, TRA 1-81, SSEA-3, SSEA-4) but express the MSC markers (CD105, CD166, CD10, CD13) along with vimentin and desmin. hES-MP cells are readily available (Cellartis) and easy to culture and represent a relatively homogenous MSC cell line that can be passaged up to 20 times without any significant loss of proliferative capacity. They show similar differentiation potential to bone marrow-derived MSCs (Karlsson et al., 2009) but perform with a higher consistency. We used this cell line as model for MSCs where there would be less variability than with primary human MSCs, and suggest they are a good cell type to use for optimisation of mechanical stimulation parameters to subsequently be used for primary adult MSCs.

Reviewer I: Do the authors believe HDFs to have a good future in bone tissue engineering?

Authors: It is not currently known whether the cells derived from a skin biopsy which undergo osteogenesis are the HDFs themselves or progenitor cells residing amongst the HDFs. There are also relatively few studies looking at the osteogenic potential of HDFs compared with those of bone marrow or adipose-derived MSCs. Some of these studies suggest that they are a potential abundant source of autologous cells for bone tissue engineering but that more in vivo studies are needed to see how well they can incorporate into bone tissue. Certainly, autologous keratinocytes have proved very valuable for treating patients with extensive skin loss due to burns, wounds or chronic ulcers (MacNeil, 2007), and more recently dermal fibroblasts have been shown to have within them a population of cells which appear to be pre-angiogenic (Krajewska et al., 2011). The latter study suggests that the HDF cultures contain progenitor cells for several differentiation pathways.

Reviewer I: How specific is SHG to collagen detection and what else might be visualised (if anything)? Do the authors see this as a simple technique that could be picked up in different labs with the right kit?

Authors: Only molecules lacking a centre of symmetry can exhibit SHG, and this is amplified with increasing organisation of the structure. Collagen is a very strong emitter of SHG and is often very well organised, e.g. in tendon, so tissues or tissue-engineered constructs containing collagen can produce SHG. It is unsure whether other tissue components produce $\mathrm{SHG}$, but if they do then it is not expected to be significant. When using multiphoton lasers to produce $\mathrm{SHG}$, there is also the possibility of unwanted two-photon fluorescence from other tissue components spilling into the SHG emission window, however with the correct filters this can be minimised. We have carried out wavelength dependant studies and found that the selection of $940 \mathrm{~nm}$ as the excitation source not only increases SHG intensity at a given power compared with other excitation wavelengths (800-1000 nm) but also removes unwanted fluorescence from other components. The equipment required to visualise $\mathrm{SHG}$ is a confocal microscope and a multiphoton laser capable of excitation at wavelengths anywhere between 700 to $1060 \mathrm{~nm}$. Using the right imaging conditions, any user familiar with confocal microscopy should be able to perform SHG easily, and as the sample requires no processing it is a very quick method for imaging collagen.

Reviewer II: With respect to the impact on the patient, how much skin would need to be removed to produce a clinically relevant number of low passage HDFs?

Authors: A small $3 \mathrm{~mm}$ skin biopsy is sufficient to extract and expand dermal fibroblasts. After 2-3 weeks of culture, tens of millions of cells will be available by passage 3 .

Reviewer IV: The rocking system only allows for oscillatory flow, not for continuous flow. This may be a disadvantage for looking at different flow modes. Please elaborate.

Authors: Yes this is true. However, in mature bone (and many other tissues in the body, such as the bone marrow), fluid flow is oscillatory in nature and so we are interested in replicating this stimulus. It is true that one could not compare, for instance, unidirectional to oscillatory flow in this system. For that one could use the parallel plate flow chamber system. However, the rocker system has many advantages in that it has simple operation, a large number of samples can be stimulated at once, and it requires small volumes of media.

\section{Additional References}

MacNeil S (2007) Progress and opportunities in tissue engineering of skin. Nature 445: 874-880.

Krajewska E, Lewis C, Staton C, MacGowan A and MacNeil S (2011) New insights into induction of earlystage neovascularisation in an improved tissue-engineered model of psoriasis. J Tissue Eng Regen Med 5: 363-374. 